\title{
Effect of Polya George's Problem Solving Model on Students' Achievement and Retention in Algebra
}

\author{
Samuel Onyinyechi Nneji \\ Department of Physical Sciences \\ Evangel University, Akaeze, Ebonyi State, Nigeria.
}

\section{Doi:10.5901/jesr.2013.v3n6p41}

\begin{abstract}
Quasi-experimental design was adopted in this study. Pretest-posttest, non equivalent control group was used. Eight intact classes, four of which were randomly assigned to experimental and the other four to control groups are used for the study. Sample of the study consisted of 220 SSII students from Ishielu Local Government Area of Ebonyi State. Four research questions and four hypotheses guided the study. Algebra Achievement Test (ALAT) was used for data collection. ALAT was constructed by the researcher and validated by three research experts. Mean and standard deviation were used to answer the research questions while the hypotheses were tested at .05 level of significance using Analysis of Covariance (ANCOVA). Experimental groups were taught using Polya George's Problem Solving Model (POGPROSMO) while control groups were taught the same topics using expository method. Major findings of the study revealed that students taught Algebra with POGPROSMO achieved higher and retained more than those taught with expository method. There was no significant difference between the mean achievement and retention scores of male and female students in the study. It was recommended that Mathematics teachers should adopt POGPROSMO in teaching Algebra.
\end{abstract}

Keywords: Achievement, Retention, Problem solving, Algebra, Education

\section{Introduction}

Obviously mathematics is a veritable tool for facilitating functional education needed to empower a person. It is therefore worrisome seeing students' consistent poor achievement and retention in this all important subject. According to Jacos (2008), academic achievement depicts students' performance on a standard of measurement such as performance test, skill test, analytical thinking test. It is therefore, not out of place to describe academic achievement as the gain in knowledge of students as a result of taking part in a learning activity or programme. Learning here refers to changes in a person's behavioural repertoire rather than just a change in behavior. Academic achievement is a result-oriented construct that encapsulates the extent of performance of a desired task. (Rix, 2010).

Retention is the noun form of the verb "Retain". Hornby (2003) defined retain as "keep"; "continue to have or hold" or "keep in place". In the same vein, Rix (2010) defined retain as "keep possession of. Retention, which is the act of retaining, maybe defined as the act of "absorbing and holding" or "or continue having or holding". In the context of this work, retention refers to the act of absorbing, holding, or continuing to hold or have facts or things learned. On problems of retention, Dulton (1975) in Ezeamenyi (2004) asserted that failure to provi9de enough applications to real life activity and social usage cum poor teaching techniques are strong limiting factors to students' retention in mathematics. Similarly, Gagne (1977) in Ezeamenyi (2004) contended that for improvement of retention of learned materials in mathematics, activity-based learning is indispensable. Retention, thus, depends mainly of teaching strategy adopted by the teacher. 
Research evidence have consistently indicated teaching method as a major factor determining the achievement and retention of students in mathematics. Hence the search for better methods and newer innovations is a great challenge facing science educators. This study therefore investigated the effect of a modern innovation, the problem solving technique on students' achievement and retention in algebra. According to Obodo (2004) problem solving technique comprises of identifying and choosing mathematical problems which grow out of the experiences of individual students, placing these problems before the students and guiding them in their solutions. It follows the steps of scientific method as well as those of reflective thinking. The teacher guides the class in solving the mathematical problem as a group. This technique allows students to learn from their successes and failures and culminates into real comprehension of facts since it permits the students to participate in their learning. The techniques also tends to force students to arrange and classify facts or data. The aim of this techniques is to inculcate in the children the habit of seeking logical answers or finding adequate pattern which solve the problem. This may imply that the technique encourages students to think for themselves and to arrive at a deeper understanding of what they have. In other words, the technique guides and stimulates the learner into discovering the solutions to certain problems which arise in their course of study by himself and to encourage the learner to reason and pass judgement in order to arrive at a reasonable solution to his problem.

Many scholars have outlined the sequence of problem solving technique and one of them is Polya George a professor of mathematics. Polya in his problem solving model in 1973 identified four stages viz; Understanding the problem, Devising a plan to solve the problem, carrying out the plan and looking back

As good as this technique may sound, research evidence still have no definitive answer to how effective it is in teaching mathematics, especially in topics like algebra which constitutes greater percentage of the secondary school Mathematics curriculum. This study therefore is, to say the least, most timely.

\section{Purpose of the Study}

The main purpose of this study was to investigate the effect of Polya George's Problem Solving Model (POGPROSMO) on secondary school students' achievement and retention in algebra. Specifically, the study investigated the effect of POGPROSMO on senior secondary School II (SSII) students

1. achievement in algebra

2. retention in algebra

3. achievement in algebra with regards to their gender and

4. retention in algebra with regards to their gender.

\section{Research questions}

The following research questions guided the study;

1. What are the mean achievement scores of students in the experimental and control groups in both pretest and posttest?

2. What are the mean retention scores of students in the experimental and control groups?

3. What are the mean achievement scores of male and female students in Experimental and Control groups in both pretest and posttest?

4. What are the mean retention scores of male and female students in experimental and control group? 


\section{Hypotheses}

The following research hypotheses were tested at .05 level of significance.

1. There is no significant difference between the mean achievement scores of students in the experimental and control groups in the posttest.

2. There is no significant difference between the mean retention scores of students in the experimental and control groups.

3. There is no significant difference between the mean achievement scores of male and female students in the experimental and control groups in the posttest.

4. There is no significant difference between the mean retention scores of male and female students in the experimental and control groups.

\section{Methodology}

The research design adopted in the conduct of this investigation was quasi-experimental design, thus, a pretest posttest, non equivalent groups was used. Eight intact classes randomly assigned to experimental and control groups were used. The area covered in this study was Ishienu Local Government Area, of Ebonyi State. The population for the study consisted of all senior secondary two (SSII) students in the area numbering three thousand and twelve $(3,012)$ as at the time of the study. Purposive sampling technique was used to draw four secondary schools, two male (boys only) and two female (girls only). Furthermore, in each of the four secondary schools two SS II intact classes were sampled randomly and assigned to experimental and control groups randomly also. The total number of 220 students in the eight SS II intact classes made up the sample of the study. The sample consisted of 118 students in the experimental group and 102 students in the control group. Similarly, the sample was made up of 104 male and 116 female students. Instrument used for data collection was Algebra Achievement Test (ALAT). This instrument was developed by the researcher. It is made up of twenty (20) multiple choice questions. The items were drawn using a table of specification to ensure adequate coverage of the content area covered in the study as well as maintain even spread across the different levels of the cognitive domain.

ALAT was validated by three research experts, one of whom was a specialist in measurement and evaluation and the other two specialists in mathematics education. ALAT was also trial - tested and the result obtained was used to calculate the reliability coefficient of .66 using KuderRichardson's formula 20 (KR-20).

\section{Experimental procedures}

The researcher trained the four regular mathematics teachers in the four secondary schools used in the study for a period of two weeks on the use of POGPROSMO. Foremost, the ALAT was administered to all the subjects of the study as pretest. Thereafter, the treatment was administered for a period of six weeks. The experimental group in each school was taught algebra using POGPROSMO while the control group in each school was taught the same topics expository method. After six weeks of treatment, the ALAT was re-arranged and administered to all the subjects as posttest. After two weeks of posttest ALAT was further re-arranged and readministered to the subject for retention scores. Mean and standard deviation were used to answer the research questions while Analysis of Covariance (ANCOVA) was used to test the hypotheses at .05 level of significance.

\section{Results}

7.1 Research question one: What are the mean achievement scores of students in the experimental and control groups in both pretest and posttest? 
Table 1: Mean achievement scores and Standard Deviations of experimental and control groups in both pretest and posttest.

\begin{tabular}{|l|c|c|c|c|c|}
\hline \multicolumn{1}{|c|}{ Group } & \multicolumn{2}{c|}{ Pretest } & \multicolumn{2}{c|}{ Posttest } & N \\
\hline & Mean & SD & Mean & SD & \\
\hline Experimental & 32 & 14.8 & 72 & 15.31 & $\mathbf{1 1 8}$ \\
\hline Control & 34 & 13.1 & 50.6 & 15.31 & 102 \\
\hline
\end{tabular}

Table 1 shows that there was no major difference between the mean achievement scores of experimental and control group in the pretest. However, experimental group apparently obtained a higher mean score of 72 than their control counterparts that achieved 50.6 as their mean achievement scores. Also the experimental group had a lower standard deviation value showing that there were less extreme scores in that group.

7.2 Research question two: What are the mean retention scores of students in the experimental and control groups?

Table 2: Mean retention scores and Standard Deviations of experimental and control groups.

\begin{tabular}{|l|c|c|c|}
\hline \multicolumn{1}{|c|}{ Group } & Mean & Standard Deviation & N \\
\hline Experimental & 66.1 & 12.8 & 118 \\
\hline Control & 44.6 & 14.6 & 102 \\
\hline
\end{tabular}

The mean retention score and standard deviations were 66.1 and 12.8 respectively for experimental group. Also the mean retention score and standard deviations were 44.6 and 14.6 respectively for control group. Obviously, the experimental group retained better also the lower standard deviation of the experimental group showed that the mean was more reliable than that of control group.

7.3 Research question three: What are the mean achievement scores of male and female students in Experimental and Control groups in both pretest and posttest?

Table 3: Pretest and Posttest achievement scores of male and female students.

\begin{tabular}{|l|}
\hline Group N Pretest Mean Std.Dev. Posttest Mean Std.Dev. \\
\hline Male (Experimental) 5018.66 .1172 .54 .01 \\
Male (Control) 5419.15 .0742 .318 .44 \\
Female (Experimental) 6818.16 .0673 .14 .20 \\
Female (Control) 4818.426 .1440 .1114 .32 \\
\hline
\end{tabular}

In the experimental group, the pretest mean achievement scores and standard deviations were 18.6 and 6.11 for male students and 18.1 and 6.06 for female students respectively. Similarly, the posttest mean achievement scores and standard deviations were 72.5 and 4.01 for male students and 73.1 and 4.20 for female students. Apparently there was no tangible difference, the standard deviations were very low for both groups, and hence both means were reliable.

However, in the control group, the pretest mean achievement scores and standard deviations were 19.1 and 5.07 for male students and 18.42 and 6.14 for female students respectively. The posttest mean achievement scores and standard deviations were 42.3 and 18.44 for male students and 40.11 and 14.32 for female students. Apparently there was no tangible difference in their performances. 


\subsection{Research Question Four: What are the mean retention scores of male and female students in experimental and control groups?}

Table 4: Mean retention scores and standard deviation scores of male and female students in the experimental and control group.

\begin{tabular}{|l|}
\hline \multicolumn{1}{|c|}{ Group N Mean Std.Dev. } \\
\hline Male (Experimental) 5066.16 .01 \\
Male (Control) 5444.87 .22 \\
\\
Female (Experimental) 6868.026 .28 \\
Female (Control) 4843.97 .01 \\
\hline
\end{tabular}

The mean retention scores and standard deviations were 63.1 and 7.12 for urban students and from the table above there is no significant difference between the mean retention scores and standard division of both groups.

\section{Hypotheses Testing}

Table 4: ANCOVA Analysis of students' achievement scores.

\begin{tabular}{|l|c|c|c|c|c|c|}
\hline Scores of variation & Sum of squares & DF & Mean Square & F & Sign of F & Decision \\
\hline Covariates & 5.770 & 1 & 5.770 & 0.032 & 0.859 & \\
\hline Pretest & 5.770 & 1 & 5.770 & 0.032 & 0.859 & \\
\hline Main effect & 12400.383 & 2 & 6200.191 & 33.861 & 0.000 & \\
\hline Method & 10269.560 & 1 & 10269.560 & 56.085 & 0.000 & S \\
\hline Gender & 6006.753 & 1 & 6006.753 & 32.805 & 0.000 & S \\
\hline 2-way & 54.567 & 1 & 54.567 & 0.297 & 0.586 & N.S \\
\hline Interactions & & 1 & & & & \\
\hline Method, Gender & 54.467 & 1 & 54.467 & 0.297 & 0.586 & \\
\hline Explained & 14432.591 & 4 & 3608.148 & 19.705 & 0.000 & \\
\hline Residual & 587777.268 & 321 & 183.107 & & & \\
\hline Total & 73209.879 & 325 & 225.26 & & & \\
\hline
\end{tabular}

Results in table four above shows that there is significant difference between the achievement of students in the experimental and control groups in favour of the experimental group. Thus, hypothesis one is rejected as stated because students taught Algebra with POGPROSMO outperformed their counterpart in the expository class. However, there was no significant difference between the achievement of male and female student in the experimental and control groups. Hence, hypothesis three is not rejected as stated, because the treatment applied on the subject affected both gender equally.

Table 5. ANCOVA Analysis of the students mean retention scores.

\begin{tabular}{|l|c|c|c|c|c|c|}
\hline Source of Variance & Sum of squares & $\mathrm{df}$ & Mean squares & F-calc. & Level of significance & Decision \\
\hline Co-variates & 514.982 & 1 & 514.982 & 39.714 & 0.000 & $\mathrm{~S}$ \\
\hline Pretest & 514.982 & 1 & 514.982 & 39.714 & 0.000 & $\mathrm{~S}$ \\
\hline Main effects & 26943.814 & 2 & 13471.907 & 811.401 & 0.000 & $\mathrm{~S}$ \\
\hline Methods & 26481.417 & 1 & 26481.417 & 2419.845 & 0.000 & $\mathrm{~S}$ \\
\hline Gender & 22944 & 1 & 22944 & 706.312 & 0.000 & $\mathrm{~S}$ \\
\hline 2-Way interaction & 152.433 & 1 & 152.433 & 0.141 & 0.768 & NS \\
\hline
\end{tabular}




\begin{tabular}{|l|c|c|c|c|c|c|}
\hline Methods*Gender & 152.433 & 1 & 152.433 & 0.141 & 0.768 & NS \\
\hline Explained & 28335.488 & 4 & 7083.872 & 432.201 & 0.000 & S \\
\hline Residual & 2003.111 & 261 & 7.675 & & & \\
\hline & & & & & & \\
\hline Total & 30338.599 & 265 & 114.485 & & & \\
\hline
\end{tabular}

$\mathrm{S}=$ Significant, NS = Not significant at 0.05 level of probability

Table 5 displays a result that shows significant effect in the mean retention scores as indicated by the F-calculated obtained. Hence, hypothesis two is rejected as stated because the experimental group retained more than their counterpart in the control group. Conversely, the $F$ - calculated for 2-way interaction between methods and gender shows no significant effect. Thus, hypothesis three is not rejected as stated because the treatment had equal effect in both gender.

\section{Summary of findings}

Here is the summary of the findings made in this study:

1. The students taught algebra with POGPROSMO achieved higher than their counterpart in the expository class.

2. The students taught algebra with POGPROSMO retained more than those in the expository class.

3. There is no significant difference between the mean achievement and retention scores of male and female students taught algebra with POGPROSMO.

\section{Discussion}

Results of data analysis shows that both groups of students had close mean and standard deviation scores in the pretest, apparently showing that they had chances of achieving equally. However, after treatment, the experimental group achieved far higher, with a lower standard deviation.

These results implicated method of teaching as a major factor affecting students' achievement in mathematics.

Similarly, there was a significant difference between the retention ability of both groups in favour of the experimental group. The experimental group retained far better than the control group. This shows that POGPROSMO enhanced the retention ability of the students better than the expository method. These results further agree with the famous Chinese proverb which stated "what I hear I forget, what I see I remember, what I do I understand."

Moreso, this result further authenticates the findings of Umar, et al (2006) and that of Eze and Egbo (2007) whose reports revealed that students taught through students-centered method retained better than those taught with the traditional lecture method. Ukeje and Obioma (2002); Ezeamenyi (2004); Obodo (2004) and Azuka (2009) all made case for the adoption of instructional methods that promote students' involvement and activity in the teaching of secondary school mathematics so as to enhance students' retentiveness.

\section{Recommendations}

Based on the findings of this study, the following recommendations are made;

1. Polya George Problem Solving Model (POGPROSMO) should be used in teaching algebra in senior secondary schools.

2. Secondary school mathematics and science teachers should be trained through intensive seminars, workshops and in-service trainings on the use of POGPROSMO for teaching and learning of mathematics.

3. Government should established mathematics laboratories in secondary schools. 


\section{References}

Abonyi, O. S. and Eze, A. O. (2007) Effect of Geo-board on junior secondary school students' interest in Geometry, Nigeria Journal of functional Education 5 (1). Nsukka: Ephrata press Production.

Adamu, H. S. (2001) Computer use in Mathematics Education. Abuja: National Mathematical Centre.

Agbo, E. A. (2004) Educational Development in Enugu State. Enugu: Fecund Printing Press.

Aghadinuno, M. C. K. (1992) Mathematics; History, Philosophy and applications to science. International Journal in Science and Technology 23 (5) 638-690.

Akinsola, M. A. Olude D. A. Oluwi, D. T (2006) Postgraduate Diploma in Education Book 7 (Mathematics). Kaduna: National Teachers' Institute.

Ale, S. O. (2009) Primary School Mathematics: A foundation for secondary level and tertiary level mathematics. Training manual for capacity building workshop for secondary and primary schools' Mathematical Science Teachers. Abuja: National Mathematical Centre.

Azuka, B. F. (2009) Active Learning in the Mathematics classroom. Training manual for capacity building workshop for secondary and primary schools' Mathematical Science Teachers. Abuja:National Mathematical Centre.

Eze, A. E. \& Egbo, J. J . (2007) Effect of concept mapping method of instruction on students' achievement and retention in Chemistry. Nigerian Journal of Functional Education 5 (1). Nsukka: Ephrata Press Production.

Ezeamaenyi, M. O. and Nneji, S. O. (2010). Effect of Computer Graphics on Students Achievement in Secondary School Mathematics. Training manual for capacity building workshop for secondary and primary schools' Mathematical Science Teachers. Abuja: National Mathematical Centre.

Ezeamaenyi,. M. V. O. N. and Alio, B. C. (2007) Identification of Mathematics topics that present difficulty to student in SSS in Awgu Local Government Area of Enugu State. Nigerian Journal of Functional Education 5 (1). Nsukka: Ephrata Press Production.

Ezeamenyi, M. V. O. N. (2004) Facing challenges of the third millennium through varieties in mathematics, science and computer Education. Enugu: Royal ventures.

Ezenweani, U. L. (1999) Relevance of Mathematics on science and Technical Education in Nigeria Universities. A paper presented at $1^{\text {st }}$ Annual Conference of Faculty of Education, Enugu State University of Science and Technology, Enugu. 1057 - 1041.

Mbaegbu, E. (2002) Technology in Mathematics Teaching/Learning. Journal of Mathematical Sciences. http://www. mathsedu.org.com.

Mgbada, C. O. (2007). Human Resource Development: The answer to the Economic Development of Izzi People of Abakaliki. Uzu: Journal of History and International Studies Vol 1 No.1: pp 66-76. The Department of History and International Studies Nnamdi Azikiwe University Awka, Nigeria.

Microsoft Encarta Encyclopedia (2005) Washinton: Microsoft Corporation.

Miller, L. E. (2010) Computer Aided Instruction (CAl). Journal of Mathematical Sciences. http://www. mathsedu.org.com.

Nduka, O. (2001) A Case for Mathematics Laboratory Techniques. Journal of Mathematical Sciences. http://www. mathsedu.org.com.

Nneji, S. O. and Okeke, C. F. (1999). Effect of Problem Solving Approach in teaching Mathematicss in Junior Secondary Schools. Science Journal vol. 1 (12). Pp 22-27. Department of Mathematics/I ntegrated science, Federal College of Education Katsina.

Nwoye, D. D. (2005) Rural/Urban Characteristics in Education. Journal of Mathematical Sciences. http://www. mathsedu.org.com.

Obodo, G. C. (2004) Principles and Practice of Mathematics Education in Nigeria. Enugu: Academic Forum.

Ogbu, S. (2006) Effect of simulation game on students' Achievement and Interest in Mathematics. Unpublished M.Sc.(Ed) Thesis. Enugu State University of Science and technology (ESUT), Enugu.

Ogbuanya, T. C. \& Usoro, A. D. (2008) Logical sequence instructional technique on academic achievement and retention of students in Technical drawing International Journal of Educational research vol. 8(1) Nsukka: University Trust Publishers.

Ogugua, E. O; Ngwu, O. G.; Olinya, N. E.; Oyedapo A. D. and Rasaki, J. O. (2008). Computer Literacy and Applications. Enugu: Hyce Kerex. 
Onuoha, J. C. and Ifelunini, I. A. (2008) Gender Gap in Secondary Education in South Eastern Nigeria: Implication for Human Capital Development. International Journal of Educational Research (INJER) vol 8(1). Faculty of Education. University of Nigeria Nsukka.

Ozofor, N. M. (2001) Effect of two Modes of computer aided instruction on Students Achievement and Interest in Statistics and Probability. Unpublished Ph.D Thesis, University of Nigeria, Nsukka.

Stuz, M. (2005) Educational Technology. Journal of Research in Science Teaching. http://www3.interscience, wiley.com/cgi-bin/abstract/112608296/ ABSTRACT.

Tsui, C. Y. and Treagust, D. (2004). Motivational aspects of learning genetics with interactive multimedia. The American Biology Teacher, 66 (1) 277 - 285.

Udeh, J.I . (2007) Computer Programming Languages. Enugu:Celex Printers \& Publishers (Nig).

Ugbo, E.C. (2005) Teaching Mathematics in Urban and Rural Schools. Kaduna: Rijiga Press

Ukeje, B. O. and Obioma, G. (2002) Mathematical Games. Abuja: National Mathematical Centre.

Umar, A; Egunjobi, S; Olude, A. O; Zubiaru, S. and Mu'azu, G. (2006). General Principles and methods in Education PDE 103. Kaduna: National Teachers' Institute. 